\title{
Dendritic cell TLR4 induces Th1-type immune response against Cryptosporidium parvum infection
}

\author{
Xu, Q.M. ${ }^{1}$, Fang, F. ${ }^{1}$, Wu, S.H. ${ }^{1}$, Shi, Z.Q. ${ }^{1}$, Liu, Z. ${ }^{1}$, Zhao, Y.J. ${ }^{1}$, Zheng, H.W. ${ }^{1,3}$, Lu, G.X. ${ }^{1}$, Kong, H.R. ${ }^{1}$, \\ Wang, G.J. ${ }^{1}$, Ai, L. ${ }^{1,2^{*}}$, Chen, M.X. ${ }^{1,2,3^{*}}$, Chen, J.X. ${ }^{2,4^{*}}$ \\ ${ }^{1}$ College of Animal Science and Technology, Anhui Agricultural University, Hefei, Anhui Province, 230036, PR China \\ ${ }^{2}$ National Institute of Parasitic Diseases, Chinese Center for Disease Control and Prevention, National Center for Tropical Diseases Research, \\ WHO Collaborating Center for Tropical Diseases, Key Laboratory of Parasite and Vector Biology, National Health and Family Planning Commission, \\ Shanghai 200025, PR China \\ ${ }^{3}$ Shenzhen Center for Disease Control and Prevention, Shenzhen 518055, PR China \\ ${ }^{4}$ National Institute of Parasitic Diseases, Chinese Center for Disease Control and Prevention-Shenzhen Center for Disease Control and Prevention \\ Joint Laboratory for Imported Tropical Disease Control, Shanghai, 200025, PR China \\ $\mathrm{Xu}, \mathrm{Q} . \mathrm{M}$. and Fang, F. contributed equally to this work. \\ *Corresponding authors: ailin08306@163.com (L. Ai); ipdchenmuxin@163.com (M.X.Chen); chenjiaxu1962@163.com (J.X.Chen)
}

\section{ARTICLE HISTORY}

Received: 20 October 2020

Revised: 20 December 2020

Accepted: 23 December 2020

Published: 25 March 2021

\begin{abstract}
The objective of this study was to investigate the mechanism of Toll-like receptor (TLR4)mediated dendritic cell (DC) immune against Cryptosporidium parvum infection. C. parvum sporozoites were labeled with 5,6-carboxyfluorescein diacetate succinimidyl ester. Murine bone marrow-derived DCs were isolated, and divided into TLR4 antibody blocking (TAB; infected with $2 \times 10^{5}$ labeled sporozoites and $0.5 \mu \mathrm{g}$ TLR4 blocking antibody), TLR4 antibody unblocking (TAU; infected with $2 \times 10^{5}$ labeled sporozoites), and blank control (BC; with 1.5 $\mathrm{mL}$ Roswell Park Memorial Institute 1640 medium) groups. The adhesion of Cryptosporidium sporozoites to DCs and CD11 $\mathrm{c}^{+}$levels were examined by fluorescence microscopy and flow cytometry. Male KM mice were orally injected with $C$. parvum. The proliferation of T lymphocytes in spleen, expression of cytokines in peripheral blood, and TLR4 distribution features in different organs were further determined by immunohistochemistry. A significantly higher expression of $\mathrm{CD} 11 \mathrm{c}^{+}$and higher $C$. parvum sporozoite adhesion were found in the TAU group compared with other groups. The expression of $C D 4^{+} \mathrm{CD} 8 / \mathrm{CD} 8^{+} \mathrm{CD} 4^{-}$in the spleen were obviously differences between the TAB and TAU groups. The expression of TLR4, interleukin IL-4, IL-12, IL-18 and IFN- $\gamma$ improved in the TAU group compared with TAB group. Higher expression of TLR4 was detected in the lymph nodes of mice in the TAU group, with pathological changes in the small intestine. Hence, TLR4 could mediate DCs to recognize C. parvum, inducing Th1 immune reaction to control $C$. parvum infection.
\end{abstract}

Keywords: Cryptosporidium parvum; Dendritic cells; Toll-like receptor; Th-1 type immune reaction.

\section{INTRODUCTION}

Cryptosporidiosis is a parasitic disease caused by Cryptosporidium spp. found in both humans and animals. It can cause acute diarrhea and is life-threatening for both immune-competent and immunocompromised individuals (Šlapeta, 2013). Although the infection is self-limiting in immunocompetent hosts, immunocompromised and malnourished individuals can develop a chronic disease (Cacciã et al., 2016). No effective therapeutic or preventive interventions have been developed for AIDS patients infected with C. parvum, in whom this disease can be fatal (Kaushik et al., 2008). Nevertheless, the exact mechanism underlying the host immune response to $C$. parvum infection is still poorly understood. Several studies have indicated that dendritic cells (DCs) are essential in recognizing, processing and presenting antigens to naïve T cells. Therefore, it is necessary to further elucidate the roles of DCs against $C$. parvum infection via Toll-like receptor 4 (TLR4).

As one of the most powerful professional antigenpresenting cells (APCs), DCs have dual roles in T cell activation (Wu et al., 2016). Immature DCs from peripheral tissues can capture external antigens and recognize them through pathogen-associated molecular patterns (PAMPs) (Acton et al., 2016; Ferreira et al., 2016). Consequently, immature DCs can migrate into lymph nodes and other immune organs, reach the maturation state, and in turn upregulate the expression of the related factors, including major histocompatibility complex (MHC)-I, MHC-II, CD86 and other costimulatory factors, as well as the expression of pro- 
inflammatory cytokines (Li et al., 2015). CD11c is one of the most important marker molecules present on the surface of DCs, and its expression is correlated with the maturation degree of DCs (Bedi et al., 2014). Several studies have suggested that cytokines induced by DCs are essential for the host defense against $C$. parvum infection. However, little is known about the potential role of pattern recognition receptors (PRRs) to cryptosporidiosis (Liu et al., 2014).

In innate immunity, Toll-like receptors (TLRs) are among the most important PRRs which can recognize a wide range of pathogens or PAMPs, including virus, bacteria, fungi and parasites (Kawai et al., 2010). For instance, TLR4 can recognize lipopolysaccharide (LPS) as the major component of the outer membrane from Gram-negative bacteria (Schneider et al., 2012). It can also identify some parasite antigens such as Plasmodium's and Toxoplasma's glycosylphosphatidylinositol (GPI), and produce a strong immune reaction. Therefore, it is considered critical in initiating defense responses to mobilize immune effector cells and activate adaptive immunity. Further, C. parvum can expose a number of glycoprotein antigens on its surface, providing the substantial basis for TLR recognition (Bogert et al., 2008; Yang et al., 2015).

However, the mechanism by which TLR4 mediates DCs response to $C$. parvum infection is still not clear. This study investigated the interaction between DCs, C. parvum and TLR4. The mouse bone marrow DCs were isolated, blocked with TLR4 antibody, and further stimulated with $C$. parvum to analyze its maturation degree in vitro. Moreover, a mouse model infected with $C$. parvum was established to evaluate the TLR4 function that resists $C$. parvum in vivo.

\section{MATERIAL AND METHODS}

\section{Animals and parasites}

Male KM mice, aged 4 weeks, were purchased from Laboratory Animal Center of Anhui Medical University, China. C. parvum oocysts were collected and purified from bovine stool using sucrose discontinuously.

All the animals were maintained at a temperature of $22^{\circ} \mathrm{C} \pm 1{ }^{\circ} \mathrm{C}$ and relative humidity of $50 \% \pm 1 \%$ under a $12 \mathrm{~h}$ light/dark cycle. All animal studies (including the mice euthanasia procedure) were performed in compliance with the regulations and guidelines of Anhui Medical University institutional animal care, and according to the Association for Assessment and Accreditation of Laboratory Animal Care (AAALAC) and the Institutional Animal Care and Use Committee (IACUC) guidelines, approval number is 2018-029.

\section{Reagents}

Fetal bovine serum was purchased from Gibco (Grand Island, NY, USA); Murine granulocyte-macrophage colony stimulating factor (GM-CSF) and interleukin 4 (IL-4) were obtained from Peprotech (London, U.K.); Anti-Mouse CD11c fluorescein isothiocyante (FITC), Anti-Mouse CD3 P-phycoerythrin (PE), Anti-Mouse CD4 Allophycocyanin (APC) and Anti-Mouse-CD8 FITC were purchased from eBioscience (San Diego, CA, USA); 5(6)-Carboxyfluorescein diacetate $\mathrm{N}$-succinimidyl ester (CFSE) were obtained from Dojindo (Japan); Anti-TLR4 antibody was obtained from Abcam (Toronto, Canada).

\section{DCs generation from bone marrow}

Bone marrow-derived DCs (BMDCs) were generated as previously described (Inaba et al., 2000). Briefly, BMDCs were cultured in RPMI 1640 medium containing 10\% fetal bovine serum at $37^{\circ} \mathrm{C}$ with $5 \% \mathrm{CO}_{2}$. Consequently, cells were induced by $5 \mathrm{ng} / \mathrm{mL}$ GM-CSF and IL-4. The culture medium was replaced every 2 days. Adherent DCs were observed after $24 \mathrm{~h}$.

\section{Excystation of $\boldsymbol{C}$. parvum and CFSE staining}

C. parvum oocysts were suspended in $0.8 \%$ sodium hypochlorite for $7 \mathrm{~min}$ and then incubated at $37^{\circ} \mathrm{C}$ for $30 \mathrm{~min}$. The cells were then washed twice in sterile phosphate-buffered Saline (PBS, $\mathrm{pH} \mathrm{7.2)} \mathrm{and} \mathrm{suspended} \mathrm{in} \mathrm{PBS} \mathrm{(pH} \mathrm{7.2)} \mathrm{containing}$ $0.8 \%$ Na-taurocholate (Solarbio, China) at $37^{\circ} \mathrm{C}$ for $30 \mathrm{~min}$. Then, excystated sporozoites were labeled with $10 \mu \mathrm{M}$ of CFSE for $30 \mathrm{~min}$, and then finally washed three times with PBS (pH 7.2) (Perez-cordon et al., 2014).

\section{Infection of DCs with C. parvum}

DCs $\left(1 \times 10^{6}\right)$ were plated into six-well plates and cultured for $6 \mathrm{~h}$. They were then divided into three groups: blank control (BC) group, TLR4 antibody blocking (TAB) group, and TLR4 antibody unblocking (TAU) group. The mice in the TAB group were infected with $2 \times 10^{5}$ labeled sporozoites and $0.5 \mu \mathrm{g}$ TLR4 antibody, in the TAU group with $2 \times 10^{5}$ labeled sporozoites, and in the BC group with $1.5 \mathrm{~mL}$ RPMI 1640 medium. The adhesion of Cryptosporidium sporozoites to DCs was examined using fluorescence microscopy $24 \mathrm{~h}$ after infection. All experiments were performed in triplicate.

\section{Determination of CD11c expression}

After $2 \mathrm{~h}$ of infection with sporozoites, $2 \times 10^{5}$ DCs were stained with $5 \mu \mathrm{L}$ anti-mouse CD11c FITC for $30 \mathrm{~min}$, washed with ice-cold PBS three times, and analyzed using flow cytometry (FACSCalibur) and CellQuest software.

\section{C. parvum infection in vivo}

The mice were divided into three groups: TLR4 antibody seal (TAS) group, treated with $10 \mu \mathrm{L}(20 \mathrm{mg} / \mathrm{mL})$ of anti-TLR4 antibody, TLR4 antibody unsealing (TAU) group, and control group. In addition, the mice in the TAS and TAU groups were administrated with $2 \times 10^{5} \mathrm{C}$. parvum oocysts using oral gavage, while the control group received the same amount of saline.

\section{Proliferation situation of $\mathrm{CD} 3 / \mathrm{CD} 4 / \mathrm{CD} 8$ and $\mathrm{qPCR}$ analysis}

To analyze the proliferation of $\mathrm{CD} 4{ }^{+} \mathrm{CD} 8^{+}$, lymphocytes were isolated from spleen cells on the 5, 8 and $12 \mathrm{dpi}$. Cell surface staining was performed using PE anti-mouse CD3, APC anti-mouse CD4, and FITC anti-mouse CD8a for $30 \mathrm{~min}$. After washing in PBS, the cells were fixed with $4 \%$ Paraformaldehyde and analyzed using FACSCalibur.

Total RNA was extracted from leukocyte using TRIzol reagent (Invitrogen, Toronto, Canada), and then reversed transcribed into cDNA using PrimeScript RT reagent Kit (TaKaRa, Japan). To examine the expression of immunerelated factors (IL-4, IL-6, IL-12, IL-18, IFN- $\gamma$ and TLR4) after infection with $C$. parvum mediated by TLR4, specific primers were designed, as shown in Table 1. Real-time quantitative polymerase chain reaction (PCR) was carried out using a 7500 Real-time PCR System (Applied Biosystems, Warrington, UK) and the SYBR Green kits (Qiagen, Germany). The amplified volume contained $10 \mu \mathrm{L}$ of $2 \times$ SYBR premix, $0.8 \mu \mathrm{L}$ of $\mathrm{CDNA}$, $0.5 \mu \mathrm{L}$ of $25 \mu \mathrm{M} \mathrm{p} 1,0.5 \mu \mathrm{L}$ of $25 \mu \mathrm{M}$ p2 and $8.2 \mu \mathrm{L}$ of $\mathrm{ddH}_{2} \mathrm{O}$, and $\beta$-actin served as the reference gene.

\section{Immunohistochemistry}

To detect the expression of TLR4 in different tissues infected with $C$. parvum, the spleen, lymph nodes and small intestine were collected from different groups on the 5, 8 and $12 \mathrm{dpi}$. All tissues were fixed with $10 \%$ formaldehyde for $24 \mathrm{~h}$ and cut into $5 \mu \mathrm{m}$ paraffin-embedded sections. A two-step immunohistochemical staining technique EnVision was used in this study. Anti-TLR4 antibody (diluted at 1:1000) was used as the primary antibody. The density of diaminobenzidine 
Table 1. Primer sequence and its optimum annealing temperatures for PCR amplifications

\begin{tabular}{|c|c|c|c|c|}
\hline Mouse target gene & Primer & Primer sequence & Annealing temperature $\left({ }^{\circ} \mathrm{C}\right)$ & Size of amplicons (bp) \\
\hline IL-4 & $\begin{array}{l}\text { IL-4-F } \\
\text { IL-4-R }\end{array}$ & $\begin{array}{l}\text { CTCTCTGTGGTGTTCTTCG } \\
\text { ATCCTGCTCTTCTTTCTCG }\end{array}$ & 60 & 174 \\
\hline IL-6 & $\begin{array}{l}\text { IL-6-F } \\
\text { IL-6-R }\end{array}$ & $\begin{array}{l}\text { TGCTGCTATCAATCCATGA } \\
\text { ACCTCCTGTTTGGCTCCA }\end{array}$ & 60 & 150 \\
\hline IL-12 & $\begin{array}{l}\text { IL-12-F } \\
\text { IL-12-R }\end{array}$ & $\begin{array}{l}\text { TGCTGCTATCAATCCATGA } \\
\text { ACCTCCTGTTTGGCTCCA }\end{array}$ & 58 & 125 \\
\hline IL-18 & $\begin{array}{l}\text { IL-18-F } \\
\text { IL-18-R }\end{array}$ & $\begin{array}{l}\text { ACTCTTGCGTCAACTTCAA } \\
\text { CCTCGAACACAGGCTGTC }\end{array}$ & 54 & 135 \\
\hline$\beta$-Actin & $\begin{array}{l}\beta \text {-Actin-F } \\
\beta \text {-Actin-R }\end{array}$ & $\begin{array}{l}\text { CTGTCCCTGTATGCCTCTG } \\
\text { ATGTCACGCACGATTTCC }\end{array}$ & 58 & 178 \\
\hline IFN- $\gamma$ & $\begin{array}{l}\text { IFN- } \gamma-\mathrm{F} \\
\text { IFN- } \gamma-\mathrm{R}\end{array}$ & $\begin{array}{l}\text { GCTCTGAGACAATGAACG } \\
\text { TTCTTCCACATCTATGCC }\end{array}$ & 60 & 145 \\
\hline TLR4 & $\begin{array}{l}\text { TLR4-F } \\
\text { TLR4-R }\end{array}$ & $\begin{array}{l}\text { CTTTATTCAGAGCCGTTGG } \\
\text { TGTCATCCTGCTCTTCTTTT }\end{array}$ & 54 & 180 \\
\hline
\end{tabular}

(DAB) with analyzed using ImageJ software and compare using average optical density.

\section{Statistical analysis}

All data were analyzed using SPSS19.0 and one-way analysis of variance. F-test was used to evaluate the differences. $P$ value less than 0.05 was considered statistically significant.

\section{RESULTS}

\section{Expression of $\mathrm{CD} 11 \mathrm{c}^{+}$in DCs after infection with $C$. parvum} $\mathrm{CD}_{11 \mathrm{c}^{+}}$is considered one of the key markers for DC maturation (Poncini et al., 2010; Bedi et al., 2014). In this study, the expression of $\mathrm{CD} 11 \mathrm{c}^{+}$was examined by flow cytometry. The expression level of $\mathrm{CD} 11 \mathrm{c}^{+}$was $83.37 \pm 3.73$ and $67.67 \pm 1.80$ in the TAB and TAU group, respectively, while it was $7.06 \%$ in BC group (Figure 1). Moreover, a significant difference was observed between the groups $(P<0.05)$. These results suggested that $C$. parvum could significantly promote the maturation of $D C$.

\section{C. parvum sporozoites adhesion to DCs}

C. parvum sporozoites labeled with CFSE were co-cultured with DCs for $24 \mathrm{~h}$. As shown in Figure 2, the adhesion was clearly visible in the TAB and TAU groups (Figure $2 \mathrm{D}$ and $2 \mathrm{E}$ ), while no signal was detected in the $B C$ group (Figure $2 F$ ). Nevertheless, a lower signal was observed in the TAB group compared with the TAU group.

\section{The proliferation of $\mathrm{CD}^{+}{ }^{+} \mathrm{CD} 4^{+} \mathrm{CD} 8-/ \mathrm{CD3}^{+} \mathrm{CD} 8^{+} \mathrm{CD} 4-\mathrm{T}$ cells}

$\mathrm{CD}^{+}{ }^{+} \mathrm{T}$ cells have an important role in resistance to $C$. parvum (McDonald et al., 2013). To examine the role of TLR4 in C. parvum infection, the expression levels of $\mathrm{CD} 3 / \mathrm{CD} 4 / \mathrm{CD} 8$ were detected at different time points, that is, on 5, 8 and $12 \mathrm{dpi}$. As shown in Figure 3 , in the group analysis, the expression of $\mathrm{CD}^{+}$was not the same on $5 \mathrm{~d}, 8 \mathrm{~d}$ and $12 \mathrm{~d}$ after infection with $C$. parvum. Also, the expression of $\mathrm{CD} 4^{+} \mathrm{CD} 8^{-}$was observed on the 8th day after infection with $C$. parvum, but the difference was not significant $(P>0.05)$. The expression of $C D 3^{+} C D 4^{+} C D 8$ was significantly higher in the TAU group compared with the $\mathrm{BC}$ and TAB group $(P<0.05)$ on the 5 and $8 \mathrm{dpi}$ (highest peak), and then it decreased. Moreover, on the 5 and $8 \mathrm{dpi}$, the expression of $\mathrm{CD}^{+}{ }^{+} \mathrm{CD} 8^{+} \mathrm{CD} 4^{-}$was significantly lower in the

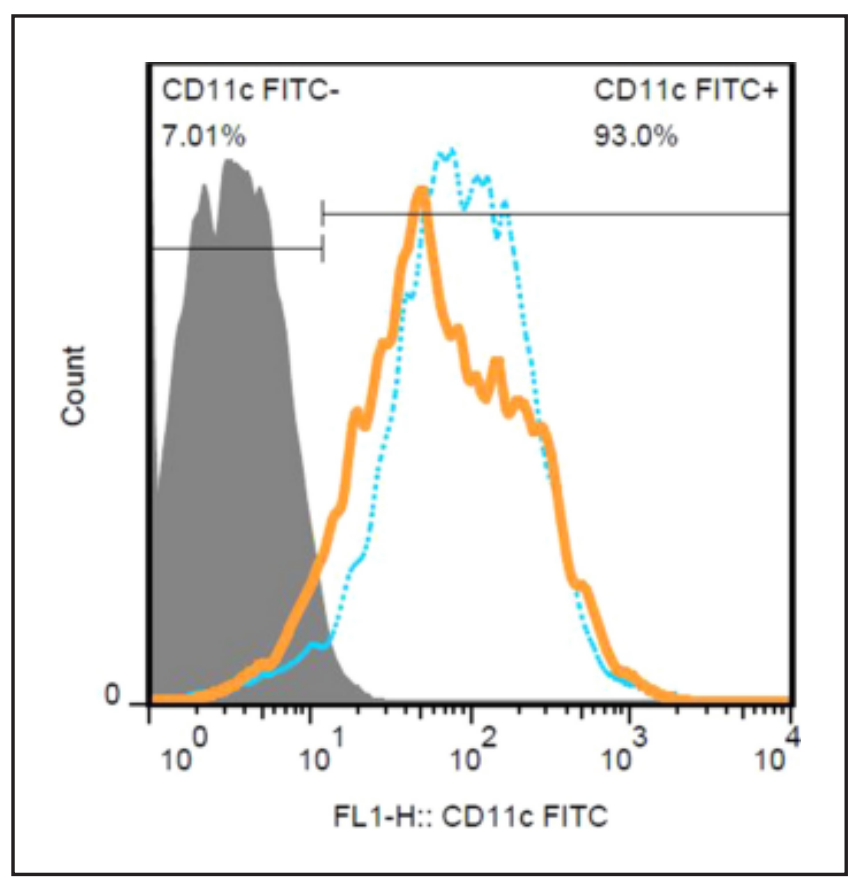

Figure 1. Expression of $C D 11 c^{+}$in $D C s$ after infection with $C$. parvum. Blue resprents TAU; orange resprents TAB; shadow resprents $B C$.

TAU group compared with the $\mathrm{BC}$ group $(P<0.05)$. On the 12 $\mathrm{dpi}$, no difference was found between groups. These data suggested that $\mathrm{CD}^{+} \mathrm{CD} 4^{+} \mathrm{CD} 8$ - could be upgraded in the early stage of $C$. parvum infection.

\section{Differences in expression of immune-related factors mediated by} TLR4

$\mathrm{CD}^{+} \mathrm{T}$ cells have been implicated as key components in immune response to $C$. parvum infection. The expression of immune-related factors was also associated with resistance to infection. Nevertheless, the effect mechanisms responsible for recovery from infection are poorly understood (Robinson et al., 2001). Futher, evidence to illustrate the role of TLR4 against $C$. parvum was not available. Therefore, the 


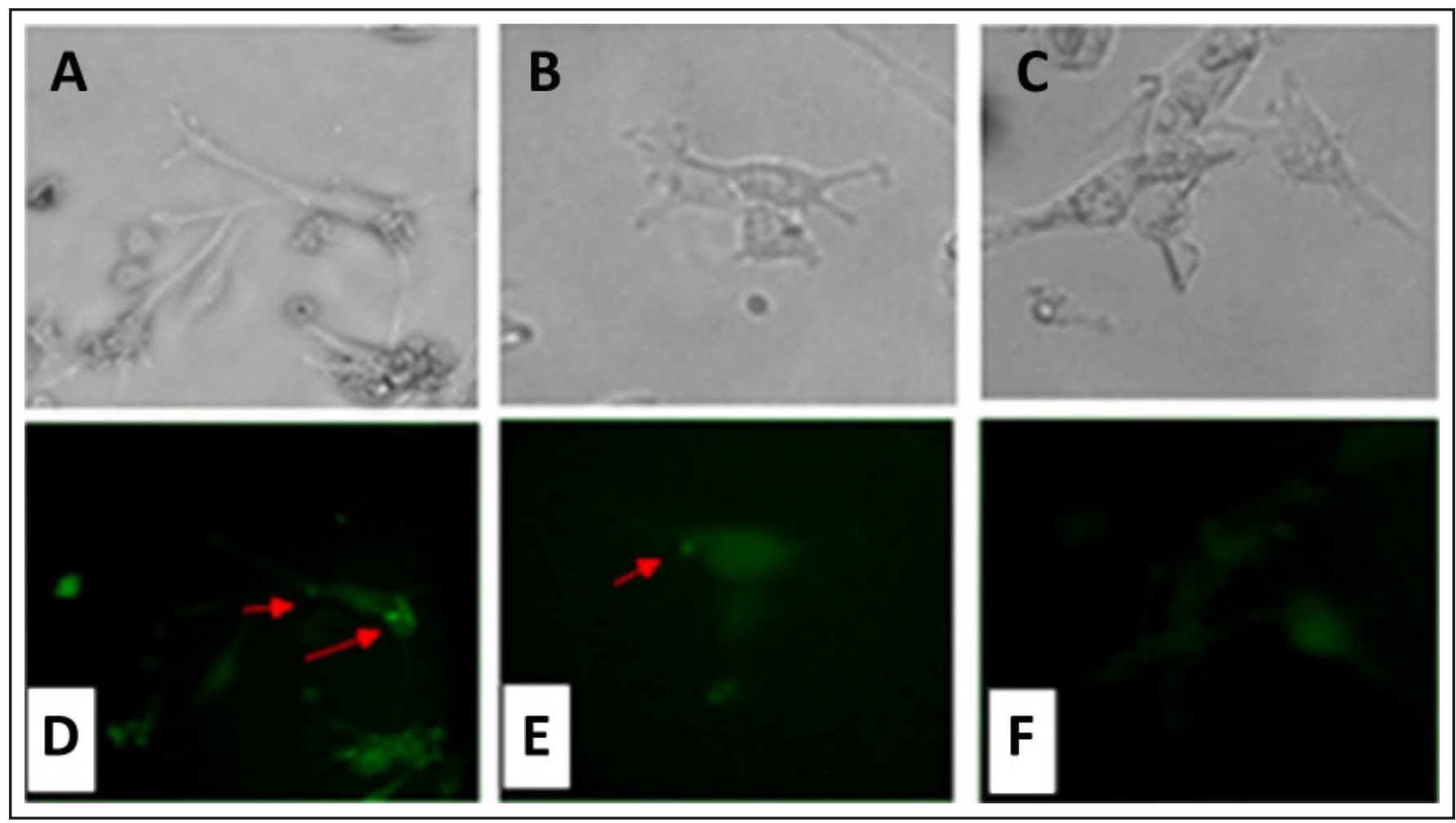

Figure 2. Adhesion between DCS and the tagged-CFSE C. parvum sporozoites. (A and D) TAU group, (B and E) TAB group, and (C and F) BC group (400x).

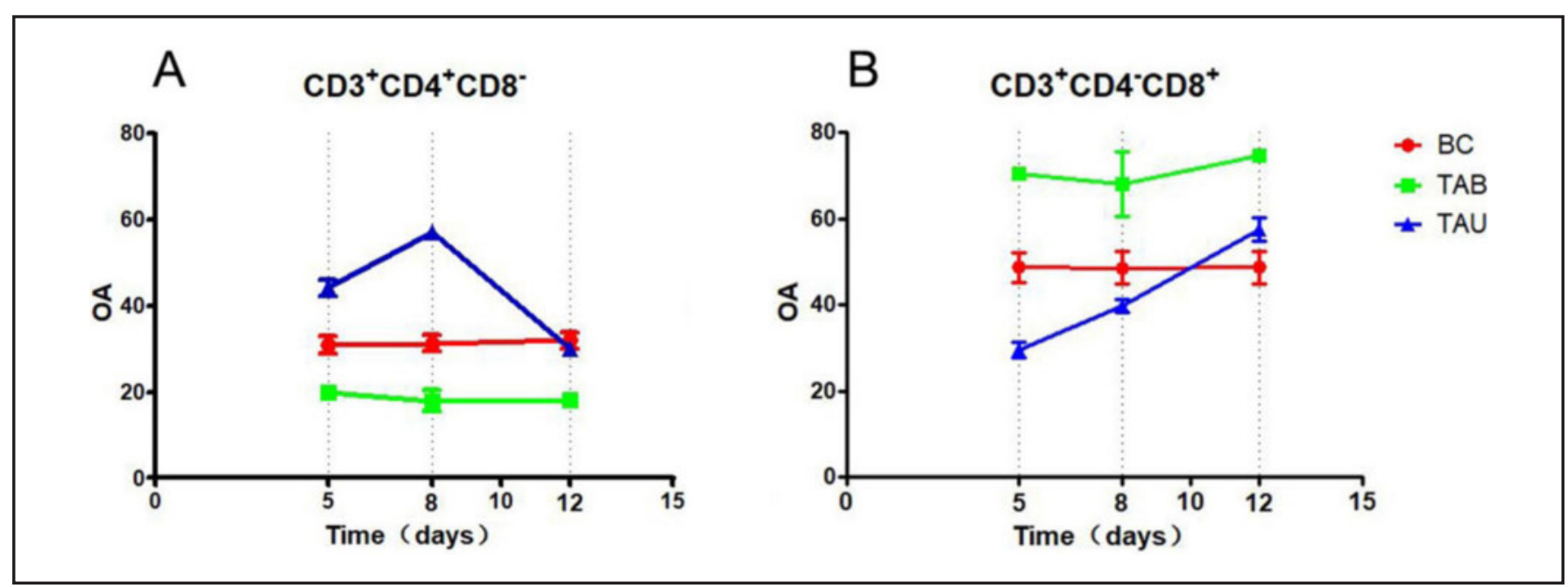

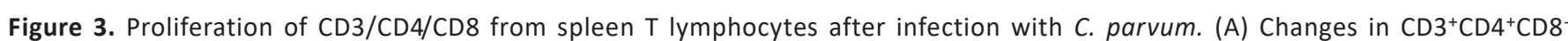
among the BC, TAB and TAU groups 5, 8 and 12 days after infection with $C$. parvum. (B) Changes in $\mathrm{CD} 3^{+} \mathrm{CD} 4{ }^{-} \mathrm{CD} 8^{+}$. Three samples were compared with PBS-injected controls. The difference analysis was performed by flow cytometry (mean \pm standard error of the mean of six biological replicates).

effects of TLR4 on the secretion of cytokines from peripheral blood examined on the 5, 8 and $12 \mathrm{dpi}$. As shown in Figure 4, the expression of immune-related factors was significantly upregulated due to $C$. parvum infection. Significantly higher expression levels of IL-4, IL-12, IL-18, IFN- $\gamma$ and TLR4 were observed in the TAU group compared with the TAB group $(P<$ 0.05 ), while no difference in the expression of IL- 6 was found between the TAU and TAB groups. For all cytokines, the highest peak was detected on the 8 dpi. These data suggested that $C$. parvum induced IL-4, IL-12, IL-18, IFN- $\gamma$ and TLR4 production. Most cytokines involves in Th1 immune response had the tendency of upregulation, but only IL-4 involved in Th2 immune response was upregulated.

\section{Immunohistochemistry reaction}

Villous damage, atrophy and reduction were observed in the intestine on $12 \mathrm{dpi}$. The surface of the intestine mucosa had the form of a crater, and a large number of shedding tissue fragments were found in the intestines. However, evidence to illustrate the changes in the expression of TLR4 in intestine after the infection of $C$. parvum was not sufficient. Hence, immunohistochemical analysis was performed to observe the expression of TLR4 in spleen, intestine and lymph node separately.

As shown in Figure 5, the highest expression of TLR4 was found in the intestine (Figure 5D-F) and lymph nodes (Figure $5 \mathrm{H}-\mathrm{I}$ ) of mice in the TAU group. The expression was 


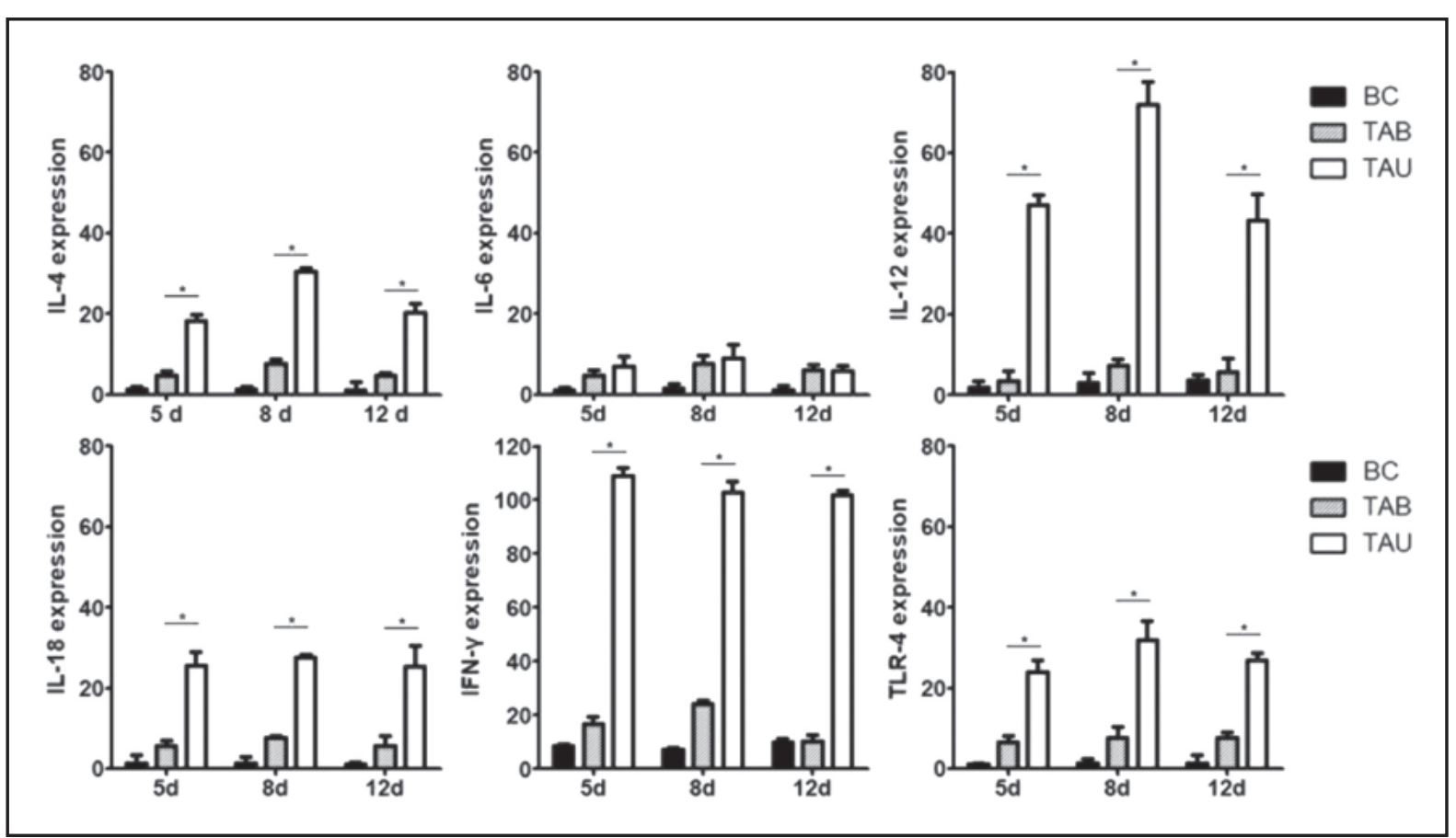

Figure 4. The expression levels of immune-related factors at different stages and in different groups after infection with $C$. parvum. The controls were treated with PBS 5, 8, $12 \mathrm{dpi}$. The T cells from peripheral blood were isolated, and the expression of IL-4, IL-6, IL-12, IL-18, IFN- $\gamma$ and TLR4 was detected using q-PCR (mean \pm standard error of the mean of six biological replicates).

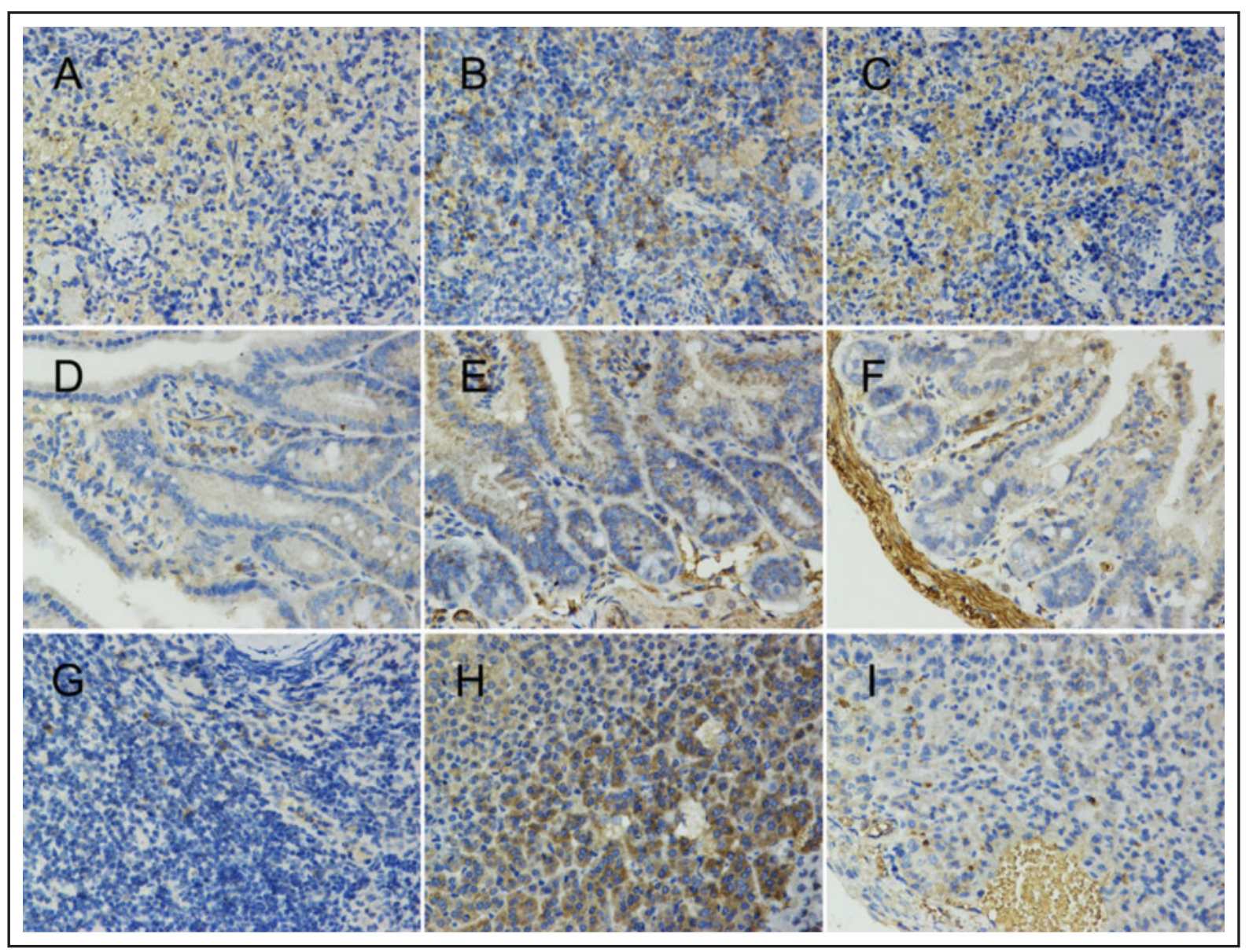

Figure 5. Expression of TLR4 (brown granules) in the spleen, intestine, and lymph nodes in different groups by immunohistochemical analysis. (A-C) The spleen samples of (A) TBA group, (B) TAU group, and (C) blank control. (D-F) The intestine samples of (D) TBA group, (E) TAU group, and (F) blank control. ( $\mathrm{H}$ and I) The lymph node samples of (H) TBA group, (G) TAU group, and (I) blank control (200x). 


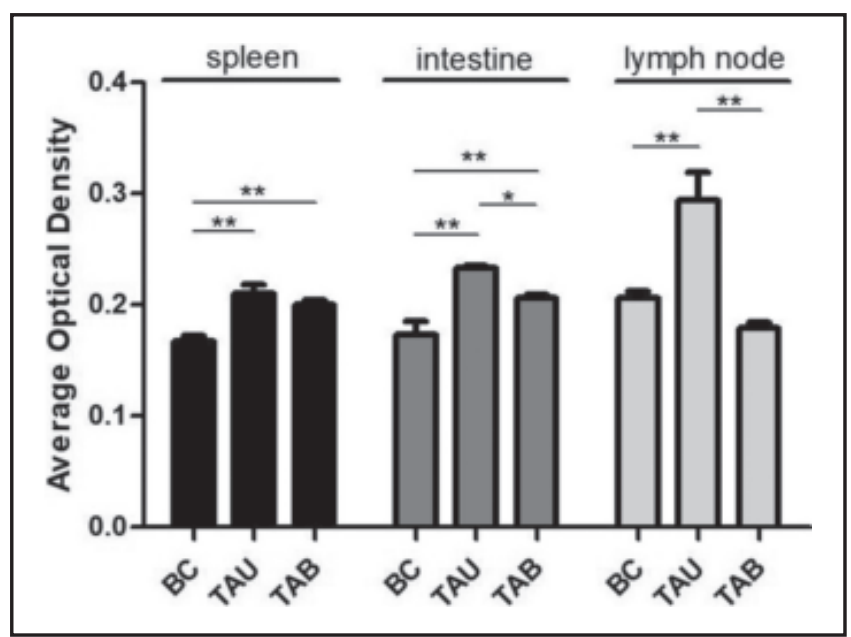

Figure 6. Quantitative analysis of TLR4 expression. Immunostaining was visualized with $D A B$, representing the expression of TLR4. The density of DAB was analyzed with ImageJ, using the average optical density for comparison.

the lowest in the control group, while no difference was found in the spleen (Figure $5 \mathrm{~A}-\mathrm{C}$ ).

Futhermore, on the $12 \mathrm{dpi}$, pathological changes was observed in the small intestine in two infection groups; in the $T A B$ group, intestinal mucosal epithelial cells were widely damaged due to villous atrophy (Figure 5 D-E).

To quantitatively analysis the expression of TLR4 in spleen, intestine, and lymph nodes on the $12 \mathrm{dpi}$, Imagel was used to determine the density of DAB. As shown in Figure 6, the optical density of TLR4 from the spleen of mice in the BC, TAU and TAB groups was $0.160,0.211,0.202$, respectively. The expression of TLR4 of was higher in the TAU and $T A B$ groups than in the $B C$ group, with significantly differences $(P<0.01)$, but no difference was found between the TAU and TAB groups $(P>0.05)$. The optical density was $0.172,0.232$, and 0.201 in the intestine. The expression of TLR4 was higher in the TAU and TAB groups than that in the BC group, with obvious difference $(P<0.01)$. In lymph nodes, the optical density was 0.293 . The expression of TLR4 in the TAU group was noticeably different from that in the TAB and $\mathrm{BC}$ groups $(P<0.01)$, but no difference was observed between the TAB and $\mathrm{BC}$ groups $(P>0.05)$.

\section{DISCUSSION}

Several studies have indicated that some parasites, such as Toxoplasma gondii and C. parvum, have the ability to migrate into DCs and exploit these cells to disseminate through the body (Lantier et al., 2013; Perez-cordon et al., 2014). In this study, CD11c marker was used to investigate the maturation of DCs in vitro. C. parvum could promote mouse DC maturation in the presence of TLR4; the expression of CD11c was five times higher in DCs expressing TLR4 (TAU group) compared with those in which TLR4 was blocked (TAB group). However, the expression of $\mathrm{CD} 11 \mathrm{c}$ was not completely blocked in the TAB group, suggesting the presence of another receptor associated with the activation, such as DC-Sign. In addition, after infecting DCs for $24 \mathrm{~h}$, a higher adhesion of $C$. parvum sporozoites to DCs was observed in the TAU group compared with the TAB group. However, once again, the adhesion of $C$. parvum sporozoites to DC was not completely inhibited in the TAB group, further suggested that TLR4 might not be the only mediator in activation of these cells.
Several mouse models have been used for investigating C. parvum infection and exploring its immune reaction in vivo. In addition, younger mice have shown to be more susceptible to C. parvum (Sayed et al., 2016; Schaefer et al., 2016). In this study, 4-week old mice were infected with $C$. parvum to investigate the role of TLR4 in inducing the immune response against $C$. parvum infection. The obtained data indicated that the discharge of the oocysts in mouse feces was the highest $5 \mathrm{dpi}$. In fact, the host infected with $C$. parvum displayed elongation when the function of TLR4 was inhibited, in turn suggesting that TLR4 was directly related to the chronic infection of $C$. parvum in vivo.

T cells have an important role in defending the host against $C$. parvum infection. $\mathrm{CD}^{+}$and $\mathrm{CD} 8^{+} \mathrm{T}$ cells appears to be an important component in host's response to $C$. parvum. CD4 T lymphocytes have been shown to be essential in preventing and controlling Cryptosporidium (Adjei et al., 2000; Mcnair et al., 2013). In this study, the expression of $\mathrm{CD}^{+}, \mathrm{CD}^{+}$ and $\mathrm{CD}^{+}$from spleen lymphocytes after infection with $C$. parvum was detected by flow cytometry. Briefly, significantly higher expression of $\mathrm{CD}^{+}$and lower expression of $\mathrm{CD} 8^{+}$were found after infection, while significantly lower expression of $\mathrm{CD}^{+}$and higher expression of $\mathrm{CD}^{+}$were found in cells in which TLR4 was blocked. Therefore, the hypothesis that TLR4 is a multifunctional protein participating in the proliferation of $T$ cells during $C$. parvum infection and their growth was proposed.

The induction of IL- 1, IL-2, IL-4, IL-5, IL-6, IL-8, IL-15, IFN- $\gamma$ and other cytokines have been reported as relative to $C$. parvum infection (Mateen et al., 2016). Among these cytokines, IFN- $\gamma$ and IL-12 have shown to be essential in the host's defense against $C$. parvum infection in mice and humans. Ehigiator et al. demonstrated that mice with variants of IL-12 could develop chronic infection with $C$. parvum (Ehigiator et al., 2005). IFN- $\gamma$ knockout mice suffered a more severe infection of $C$. parvum compared with the control mice (Ehigiator et al., 2007). Additionally, activated DCs have shown the ability to release IL-12 and IFN- $\gamma$ in response to various infections (Xu et al., 2017). Robinson et al. indicated that TLR4, IL-4 and IL- 6 were involved in the clearance of Cryptosporidium (Robinson et al., 2001). In this study, the expression levels of TLR4, IL-6, IL-4, IL-12, IFN- $\gamma$ and IL-18 in the peripheral blood were detected after infection using q-PCR. The expression of these factors was significantly upregulated after infection with $C$. parvum. Further, significantly higher expression levels of IL-4, IL-12, IL-18, IFN- $\gamma$ and TLR4 were observed in the TAU group compared with the TAB group $(P<0.05)$, while no difference in the expression of IL- 6 was found between the TAU and TAB groups. These data suggested that $C$. parvum induced TLR4 to enhance the expression of IL-12, IL-18 and IFN- $\gamma$, thus activating Th1-type immune response, and it was predominant. In addition, IL-4 also could be induced at the higher expression level. The findings also showed that Th2type immune response could be activated.

C. parvum is a well-known intestinal parasite that can cause severe pathological changes in the gastrointestinal tract of the host (Kosik-Bogacka et al., 2012). In this study, an immunohistochemical approach was used to further investigate the pathological changes in murine gut infected with $C$. parvum. Briefly, serious damage to the mucosal structure, shorter villus, and a large number of shedding intestinal epithelial cells were found in small intestine compared with uninfected control mice. Further, high expression of TLR4 was observed in the spleen, intestine and lymph nodes of mice infected with $C$. parvum. 


\section{CONCLUSIONS}

In conclusion, following activation with TLR4, TLR4-mediated DCs recognize $C$. parvum once it invades the host, playing a fundamental role in host innate and adaptive immunity instead of capturing and submitting antigens. Moreover, activated DCs promote the proliferation of $\mathrm{CD} 4^{+} \mathrm{T}$ cells to release Th1-type cytokines and resist $C$. parvum infection.

\section{ACKNOWLEDGMENTS}

This study was supported by the key research project of National Foundation for Science and Technology (Grant No. 2018YFD0500100, 2018YFD0502006 and 2016YFC1202700), the Natural Science Foundation of Anhui (Grant No. KJ2016A838), the Natural Science Foundation of Shanghai (Grant No. 18ZR1443500), the General Program Shanghai Municipal Commission of Health and Family Planning of China (No. 201840286 and 201640278), the Youth Science Foundation of Chinese Center for Disease Control and Prevention (No. 2018A105), Shenzhen San-Ming Project for prevention and research on vector-borne diseases (SZSM201611064), the Fifth Round of Three-Year Public Health Action Plan of Shanghai (Grant No. GWV-10.1-XK13), the Open project of Key Laboratory of Tropical Disease Control (Sun Yat-sen University), Ministry of Education (Grant No. 2019kfkt02), and the Key Laboratory of Echinococcosis Prevention and Control (Project No. 2020WZK2002).

\section{Conflicts of interest}

The authors declare no conflicts of interest with regards to this study or the manuscript prepared for publication.

\section{REFERENCES}

Acton, S.E. \& Reis e Sousa, C. (2016). Dendritic cells in remodeling of lymph nodes during immune responses. Immunological Reviews 271: 221-229. https://doi.org/10. 1111/imr.12414

Adjei, A.A., Curran, B.C., Castro, M., Shrestha, A.K., Delsid, L., Fritz, H., Velez, M. \& Enriquez, F.J. (2000). Gammadelta ${ }^{+} T$ cells and $65-\mathrm{kDa}$ heat shock protein expression following Cryptosporidium parvum challenge in athymic C57BL/6J nude mice. Immunology Letters 72: 35-38. https://doi.org/10.1016/ s0165-2478(00)00150-4

Bedi, B., Mcnair, N.N. \& Mead, J.R. (2014). Dendritic cells play a role in host susceptibility to cryptosporidium parvum infection. Immunology Letters 158: 42-51. https://doi.org/ 10.1016/j.imlet.2013.11.015

Bogert, P.S., O'hara, S.P., Trussoni, C.E., Stroope, A.J., Lewis, J.T., Chen, X.M. \& Larusso, N.F. (2008). M1746 Toll-Like Receptor 4-Mediated Immune Response Is Required for In Vivo Eradication of $C$. Parvum Infection of the Biliary Tract. Gastroenterology 134: A-410. https://doi.org/10.1016/S00165085(08)61917-4

Cacciã, S.M. \& Chalmers, R.M. (2016). Human cryptosporidiosis in europe. Clinical Microbiology and Infection 22: 471-480. https://doi.org/10.1016/j.cmi.2016.04.021

Ehigiator, H.N., Mcnair, N. \& Mead, J.R. (2007). Cryptosporidium parvum: the contribution of th1-inducing pathways to the resolution of infection in mice. Experimental Parasitology 115: 107-113. https://doi.org/10.1016/j.exppara.2006.07.001

Ehigiator, H.N., Romagnoli, P., Borgelt, K., Fernandez, M., McNair, N., Secor, W.E. \& Mead, J.R. (2005). Mucosal cytokine and antigen-specific responses to Cryptosporidium parvum in IL-12p40 KO mice. Parasite Immunology 27: 17-28. https://doi.org/10.1111/j.1365-3024.2005.00736.x
Ferreira, J., Gasparinho, M.G. \& Fonseca, R. (2016). Cytomorphological features of blastic plasmacytoid dendritic cell neoplasm on FNA and cerebrospinal fluid cytology: a review of 6 cases. Cancer Cytopathology 124: 196-202. https://doi.org/10.1002/cncy.21645

Inaba, K., Turley, S., Iyoda, T., Yamaide, F., Shimoyama, S., Reis e Sousa, C., Germain, R.N., Mellman, I. \& Steinman, R.M. (2000). The formation of immunogenic major histocompatibility complex class II-peptide ligands in lysosomal compartments of dendritic cells is regulated by inflammatory stimuli. The Journal of Experimental Medicine 191: 927-936. https://doi.org/10.1084/jem.191.6.927

Kaushik, K., Khurana, S., Wanchu, A. \& Malla, N. (2008). Evaluation of staining techniques antigen detection and nested PCR for the diagnosis of cryptosporidiosis in HIV seropositive and seronegative patients. Acta Tropica 107: 1-7. https://doi.org/10.1016/j.actatropica.2008.02.007

Kawai, T. \& Akira, S. (2010). The role of pattern-recognition receptors in innate immunity: update on Toll-like receptors. Nature Immunology 11: 373-384. https://doi.org/ 10.1038/ni.1863

Kosik-Bogacka, D.I., Wojtkowiak-Giera, A., Kolasa, A., Baranowska-Bosiacka, I., Lanocha, N., Wandurska-Nowak, E., Izabela, G., Salamatin, R. \& Jagodzinski, P.P. (2012). Hymenolepis diminuta: analysis of the expression of Tolllike receptor genes TLR2 and TLR4 in the small and large intestines of rats. Experimental Parasitology 130: 261-266. https://doi.org/10.1016/j.exppara.2011.12.002

Lantier, L., Lacroix-Lamandé, S., Potiron, L., Metton, C., Drouet, F., Guesdon, W., Gnahoui-David, A., Le Vern, Y., Deriaud, E. \& Fenis, A. (2013). Intestinal $\mathrm{CD} 103^{+}$dendritic cells are key players in the innate immune control of Cryptosporidium parvum infection in neonatal mice. PLOS pathogens 9: e1003801. https://doi.org/10.1371/journal. ppat.1003801

Li, J., Wang, X., Wang, W., Luo, J., Aipire, A., Li, J. \& Zhang, F. (2015). Pleurotus ferulae water extract enhances the maturation and function of murine bone marrow-derived dendritic cells through TLR4 signaling pathway. Vaccine 33: 1923-1933. https://doi.org/10.1016/j.vaccine.2015.02.063

Liu, J., He, C., Zhou, H., Xu, Y., Zhang, X., Yan, J., Xie, H. \& Cheng, S. (2014). Effects of TLR4 on $\beta 2$-glycoprotein I-induced bone marrow-derived dendritic cells maturation. Cellular Immunology 290: 226-232. https://doi.org/10.1016/j. cellimm.2014.07.006

Mateen, S., Zafar, A., Moin, S., Khan, A.Q. \& Zubair, S. (2016). Understanding the role of cytokines in the pathogenesis of rheumatoid arthritis. Clinica Chimica Acta 455: 161-171. https://doi.org/10.1016/j.cca.2016.02.010

McDonald, V., Korbel, D.S., Barakat, F.M., Choudhry, N. \& Petry, F. (2013). Innate immune responses against Cryptosporidium parvum infection. Parasite Immunology 35: 55-64. https:// doi.org/10.1111/pim.12020

Mcnair, N.N. \& Mead, J.R. (2013). CD4 ${ }^{+}$effector and memory cell populations protect against Cryptosporidium parvum infection. Microbes and Infection 15: 599-606. https://doi.org/ 10.1016/j.micinf.2013.04.009

Perez-cordon, G., Yang, G., Zhou, B., Nie, W., Li, S., Shi, L., Tzipori, S. \& Feng, H. (2014). Interaction of Cryptosporidium parvum with mouse dendritic cells leads to their activation and parasite transportation to mesenteric lymph nodes. Pathogens and Disease 70: 17-27. https://doi.org/10.1111/ 2049-632X.12078

Poncini, C.V., Giménez, G., Pontillo, C.A., Alba-Soto, C.D., de Isola, E.L., Piazzón, I. \& Cappa, S.M. (2010). Central role of extracellular signal-regulated kinase and toll-like receptor 4 in IL-10 production in regulatory dendritic cells 
induced by trypanosoma cruzi. Molecular Immunology 47: 1981-1988. https://doi.org/10.1016/j.molimm.2010.04.016

Robinson, P., Okhuysen, P.C., Chappell, C.L., Lewis, D.E., Shahab, I., Lahoti, S. \& White, A.C. (2001). Expression of IL-15 and IL-4 in IFN- $\gamma$-independent control of experimental human Cryptosporidium parvum infection. Cytokine 15: 39-46. https://doi.org/10.1006/cyto.2001.0888

Sayed, F.G., Hamza, A.I., Galal, L.A., Sayed, D.M. \& Gaber, M. (2016). Virulence of geographically different Cryptosporidium parvum isolates in experimental animal model. Annals of Parasitology 62: 221-232. https://doi.org/10.17420/ ap6203.56

Schaefer, D.A., Betzer, D.P., Smith, K.D., Millman, Z.G., Michalski, H.C., Menchaca, S.E., Zambriski, J.A., Ojo, K.K., Hulverson, M.A. \& Arnold, S.L. (2016). Novel bumped kinase inhibitors are safe and effective therapeutics in the calf clinical model for cryptosporidiosis. The Journal of Infectious Diseases 214: 1856-1864. https://doi.org/10.1093/ infdis/jiw488

Schneider, L.P., Schoonderwoerd, A.J., Moutaftsi, M., Howard, R.F., Reed, S.G., de Jong, E.C. \& Teunissen, M.B. (2012). Intradermally administered TLR4 agonist GLA-SE enhances the capacity of human skin DCs to activate T cells and promotes emigration of Langerhans cells. Vaccine 30: 4216-4224. https://doi.org/10.1016/j.vaccine. 2012.04.051

Šlapeta, J. (2013). Cryptosporidiosis and Cryptosporidium species in animals and humans: a thirty colour rainbow? International Journal for Parasitology 43: 957-970. https:// doi.org/10.1016/j.ijpara.2013.07.005

Wu, Y., Cui, J., Zhang, X., Gao, S., Ma, F., Yao, H., Sun, X., He, Y., Yin, Y. \& Xu, W. (2016). Pneumococcal DnaJ modulates dendritic cell-mediated Th1 and Th17 immune responses through toll-like receptor 4 signaling pathway. Immunobiology 222: 384-393. https://doi.org/10.1016/j.imbio. 2016.08.013

Xu, L., Kwak, M., Zhang, W., Lee, P.C. \& Jin, J.O. (2017). Timedependent effect of $E$. coli LPS in spleen DC activation in vivo: Alteration of numbers expression of co-stimulatory molecules production of pro-inflammatory cytokines and presentation of antigens. Molecular Immunology 85: 205213. https://doi.org/10.1016/j.molimm.2017.02.017

Yang, Z., Fu, Y., Gong, P., Zheng, J., Liu, L., Yu, Y., Li, J., Li, H., Yang, J. \& Zhang, X. (2015). Bovine TLR2 and TLR4 mediate Cryptosporidium parvum recognition in bovine intestinal epithelial cells. Microbial Pathogenesis 85: 29-34. https:// doi.org/10.1016/j.micpath.2015.05.009 